\title{
PENGARUH JUMLAH BIAYA BAHAN BAKU TERHADAP LABA BRUTO PERUSAHAAN PT PANPLY KABUPATEN LUWU
}

\author{
SALMAWATI, I KETUT PATRA, SAPAR
}

\begin{abstract}
ABSTRAK
Biaya merupakan komponen yang sangat penting dalam pertimbangan kebijakan suatu perusahaan mengambil keputusan. Semua kegiatan ekonomi yang dilakukan oleh sebuah sebuah perusahaan tidak akan terlepas dari sejumlah biaya yang dikeluarkan. Salah satu komponen biaya yang dikeluarkan adalah biaya bahan baku termasuk harga beli bahan baku, ongkos angkut, dan baiay gudang. Jumlah biaya bahan baku merupakan factor yang berpengaruh terhadap lana bruto.

Tujuan penelitian ini adalah untuk mengetahui pencapaian laba bruto pada PT Panply Kabupaten Luwu serta untuk mengetahui pengaruh antara jumlah antara biaya bahan baku terhadap laba bruto PT Panply Kabupaten Luwu. Berdasarkan masalah penelitian tersebut metode yang digunakan adalah metode regresi linear sederhana dengan memecahkan permasalahan tersebut. Tekhnik pengumpulan data yang digunakan dalam penelitian ini adalah dengan penelitian kepustakaan dan penelitian lapangan yang terdiri dari wawancara, observasi, dan dokumentasi. Pada penelitian ini, data yang dianalisis bersumber dari biaya bahan baku, penjualan, dan harga pokok penjualan PT Panca Usaha Plywood dari tahun 2007-2011.

Hasil penelitian mengenai Pengaruh Jumlah Biaya Bahan Baku Terhadap Laba Bruto perusahaan PT Panply Kabupaten Luwu. Menyatakan bahwa jumlah biaya bahan baku kadang mengalami peningkatan dan penurunan tiap tahunnya disebabkan oleh factor harga bahan baku yang biasa mengalami peningkatan serta jumlah stock bahan baku yang digunakan.

Berdasarkan hasil analisis statistik diperoleh koefisien Korelasi sebesaar 0,95 hal ini menunjukkan bahwa variable bebas (X) memberikan kontribusu terhadap variable terikat (Y) sebesar 95\%. Pengaruh positif ini menunjukkan bahwa perubahan variable bebas akan searah dengan perubahan laba bruto.
\end{abstract}

Kata kunci : Biaya bahan baku (X) dan laba Bruto PT Panply Kabupaten Luwu (Y). 


\section{Pendahuluan}

Latar Belakang

Pertumbuhan ekonomi sutua bangsa memerlukan pola pengaturan pengolahan sumber-sumber ekonomi yang tersedia secara terarah dan terpadu. Salah satu aspek penting yang harus diperhatikan dalam menjaga kesinambungan usaha adalah mengatur keuangan dalam anggaran biaya. Dalam perusahaan yang mempunyai kegiatan produksi, biaya bahan baku memiliki peranan yang sangat penting terhadap perolehan laba, karena perusahaan dapat berfungsi dengan melakukan produksi jika biaya bahan baku yang dimiliki memadai.

Laba merupakan salah satu tujuan organisasi perusahaan yang bisa dijadikan sebagai ukuran keberhasilan atau kemajuan suatu perusahaan. Maka dari itu perusahaan akan berusaha untukmenghasilkan laba agar bisa mempertahankan kelangsungan usahanya demi keberhasialan perusahaan. Laba kotor merupakan salah satu dari berbagai macam laba yang ada pada perusahaan manufaktur.

Jumlah biaya bahan baku mempunyai pengaruh yang sangat penting bagi tercapainya target laba kotor, dikemukakan oleh Irma Zuriyanna Maghfira (2004:01). Jika perusahaan bisa menggunakan biaya bahan baku secara efisien, maka akan berpengaruh terhadap pencapaian laba kotor.

Uraian diatas dapat ditarik kesimpulan bahwa pengaruh biaya bahan baku terhadap laba sangat penting dalam mewujudkan tujuan perusahaan dalam peningkatan laba Bruto. Berdasarkan tersebut diatas penulis memilih judul "Pengaruh Jumlah Biaya Bahan Baku Terhadap laba Bruto Perusahaan PT Panply Kabupaten Luwu”. Masalah dalam penelitian adalah bagaimana pencapaian Laba Bruto pada PT Panply Kabupaten Luwu dan bagaimana Pengaruh Jumlah Biaya Bahan Baku Terhadap peningkatan laba Bruto pada Perusahaan PT Panply Kabupaten Luwu. Tujuan penelitian ini adalah untuk mengetahui pencapaian laba bruto pada PT Panply Kabupaten Luwu dan untuk mengetahui Pengaruh antara Jumlah Biaya Bahan Baku Terhadap laba Bruto pada PT Panply Kabupaten Luwu.

\section{Metode Penelitian}

\section{Lokasi Penelitian}

Penelitian ini dilaksanakan di Kabupaten Luwu Kecamatan Bua tepatnya pada perusahaan PT Panply.

Jenis dan Sumber Data

1. Data Primer

Data yang diperoleh langsung melalui penelitan lapangan atau pengamatan lansung, wawancara lansung dengan karyawan, maupun obserpasi terhadap sumber data yang dibutuhkan. 


\section{Data Sekunder}

Data yang diperoleh melalui buku-buku literature atau buku bacaan lainnya.

\section{Populasi Dan Sempel}

Populasi pnelitian ini adalah seluruh laporan jumlah biaya bahan baku, penjualan, dan harga pokok penjulan PT. Panply kabupaten luwu. Sampel penelitian ini adalah laba bruto PT. panply tahun 2007 sampai dengan tahun 2011.

\section{Metode Pengumpulan Data}

Metode pengumpulan data yang digunakan dalam penelitian adalah: (a) Penelitian lapangan (field research); Penelitian yang dilakukan dengan jalan pengamatan langsung ke lapangan atau objek penelitian dengan cara mngdakan wawancara (interview). (b) Penelitian kepustakaan (library research); Penelitian yang dilakukan dengan cara mencari referensi yang berupa bukun, majalah, surat kabar, teori-teori lain yang adabungannya dengan masalah yany dibahas.

\section{Metode Analisis Data}

Salah satu metode analisa data yang lebih efisien dan efektif dalam melakukan penelitian adalah dengan menggunakan tehknik statistik.

Tekhnik analisa data yang penulis gunakan dalam penelitian ini adalah tekhnik data kantitatif yaitu suatu analis atau serangkaian pengukuran yang dinyatakan dalam angka-angka dan menghasilkan statement yang bersifat kuantitatif sehingga menjelaskan hubungan antara variable yang diteliti

\section{Hasil Penelitian Dan Pembahasan}

Untuk mengetahui pengaruh jumlh biaya bahan baku terhadap laba bruto pada PT. panply kabupaten luwu, maka dapat diketahui dengan melihat perkembangan jumlah biaya bahan baku yang digunakan dari tahun ke tahun, untuk lebih jelasnya dapat dilihat pada table berikut:

Tabel 1: jumlah biaya bahan baku yang digunkan PT. panca usaha palopo plywood tahun 2007-2011

\begin{tabular}{|c|c|}
\hline Tahun & $\begin{array}{c}\text { Jumlah biaya bahan baku } \\
(\mathrm{Rp})\end{array}$ \\
\hline 2007 & 228.627 .648 .000 \\
\hline 2008 & 419.685 .172 .000 \\
\hline 2009 & 980.904 .936 .000 \\
\hline 2010 & 575.465 .940 .000 \\
\hline 2011 & 790.813 .000 .000 \\
\hline
\end{tabular}

Sumber data: PT. Panca Usaha palopo plywood

Dengan melihat tabel diatas maka dapat dijelaskan bahwa, pada tahun 2007 jumlah biaya bahan baku PT. panca usaha palopo plywood adalah Rp 
228.627.648.000, kemudian pada tahun 2008 mengalami peningkatan yakni Rp 419.685.172.000. pada tahun 2009 juga mengalami peningkatan yakni Rp 980.904.936.000. pada tahun 2010 mengalam penurunan yakni Rp 575.465.940.000. sedangkan pada tahun 2011 mengalami peningkatan yaitu sebesar RP 790.813.000.000.

Tabel 3: Pekembangan laba bruto PT panply Kabupaten luwu 2007-2011

\begin{tabular}{|c|c|c|}
\hline Tahun & Laba bruto & Perkembangannya \% \\
\hline 2007 & 1.574 .092 .000 .000 & \\
\hline 2008 & 1.680 .085 .000 .000 & 0,06 \\
\hline 2009 & 3.263 .021 .800 .000 & 0,94 \\
\hline 2010 & 2.681 .668 .260 .000 & 0,17 \\
\hline 2011 & 3.340 .050 .000 .000 & 0,24 \\
\hline Jumlah & 12.538 .917 .060 .000 & 1,41 \\
\hline Rata-rata & 2.507 .783 .412 .000 & 0,28 \\
\hline
\end{tabular}

Data :Sudah diolah

Dengan melihat table diatas maka dapat dijelaskan bahwa, pada tahun 2007 laba bruto yang dihasilkan perusahaan PT. Panly Kabupaten Luwu adalah Rp 1.574.092.000.000. kemudian pada tahun 2008 megalami peningkatan yakni $\mathrm{Rp}$ 1.680.085.000.000 atau meningkat sebesar 6\% . pada tahu 2009 mengalami peningkatan yakni Rp 3.263.021.800.000 atau mengalami keanikan sebesar 94\%. Pada tahu 2010 mengalami penurunan yakni Rp 2.681.668.260.000 atau menurun sebesar $17 \%$. pada tahun 2011 mengalami peningkatan sebesar Rp 3.340.050.000.000.

Jadi dirata-ratakan, laba bruto PT Panply Kabupaten Luwu untuk setiap tahunnya mencapai $\mathrm{Rp}$ 2.507.783.412.000 dengan rata-rata kenaikan $28 \%$.

Dan untuk mengatahui pengaruh jumlah biaya bahan baku terhadap laba bruto PT. Panply Kabupaten Luwu maka digunakan rumus analis regresi liniear sederhana (sugiono:2008:272) dengan rumus sebagai berikut:

$\mathrm{Y}=\mathrm{a}+\mathrm{bX}$

Dimana :

$\mathrm{X}=$ jumlah biaya bahan baku

$\mathrm{Y}=$ estimasi laba bruto

$\mathrm{a}=$ konstanta

$\mathrm{b}=$ besarnya perubahan $\mathrm{Y}$ untuk satu perubahan $\mathrm{X}$

Dari hasi analisis diperoleh nilai $r$ (korelasi/hubugan) antara jumlah biaya bahan baku debgan laba bruto adalah sebesar 0,95 ini menunjukkan bahwa hubungan biaya bahan baku terhadap lab bruto adalah sangat kuat. 


\section{Penutup}

Kesimpulan penelitian ini adalah: (a) Pencapaian laba bruto PT. Panply pada tahun 2007-2011 sebesr Rp 12.538.917.060.000, atau mengalami penigkatan sebesar 95\%, (b) Jumlah biaya bahan baku berpengaruh terhadap laba bruto, dimana $\mathrm{Y}=3.548+4,18 \mathrm{X}$ yan menunjukkan bahwa $\mathrm{a}=3.548$ adalah bilangan konstanta, $\mathrm{b}=4,18$ adalah bilangan koefisien regresi variable bebas $\mathrm{X}$. Adapun saran dari penelitian ini adalah: (a) Untuk meningkatkan laba, perusahaan dapat meminimalkan biaya bahan baku, sehingga laba bruto yang dihasilakan dapat meningkat seperti ditahun sebelumnya, (b) Pihak perusahaan seharusnya memperhatikan biaya bahan baku, karena bahan baku mempunyai pengaruh terhadap peningkatn laba bruto.

\section{Daftar Pustaka}

Bridwan, Zaki. 2000, Sistem Akuntansi. Edisi 5. BPFE. Yogyakarta.

Fess, Warrant, Niswonger. 1999. Prinsip-prinsip Akuntansi, edisi 19, cetakan pertama, Erlangga. Jakarta.

Gunawan Adisaputro dan Marwan Asri. 2003. Anggaran Perusahaan. Buku 1. Yogyakarta: BPFE-Yogykarta.

Harnanto, Zulkifli. 2003. Manajemen Sumber Daya Manusia, Jakarta. Bumi Aksara

Hansen, Mowen . diterjemahkan oleh Dewi FitriaSari dan Deny Armos Kwary. 2004. Akuntansi Manajemen. Edisi ke - enam Jakarta: Salemba empat.

Henry Simamora," Akuntansi Manajemen " . edisi 2, UPP AMP YKPN, Jakarta:2002.

Horngren, Foster, Datar, ahli bahasa Desi AnDriani, 2000 "Akuntansi Biaya”. Jakarta: Indexs.

Kholmi, Masiya, 2003, Akuntansi Biaya, Universitas Muhammadiayah, UMM press, Malang. 